\title{
Silagem de capim-piatã (Brachiaria brizanta) utilizando níveis de resíduo de fibra de Curauá (Ananas Erectifolius L.B. Smith)
}

\section{Piatã grass silage (Brachiaria brizanta) using Curauá fiber residue (Ananas erectifolius L.B. Smith)}

Bárbara Eduarda Albarado de Araújo ${ }^{*}$, Adarlan Gomes Silva ${ }^{1}$, Daniel Parente Barbosa ${ }^{2}$, Ione Iolanda dos Santos ${ }^{1}$, Andréa Krystina Vinente Guimarães ${ }^{1}$.

\section{RESUMO}

O trabalho buscou avaliar as características fermentativas, análise sensorial e estabilidade aeróbia de silagens de capim-piatã com adição de resíduo de fibra de curauá. Realizou-se o experimento no laboratório de Bromatologia da Universidade Federal do Oeste do Pará, ensilou-se o capim-piatã aos 43 dias de rebrota, com inclusão de 0;2,5; 5 e 7,5\% de resíduo de fibra de curauá. Utilizou-se delineamento inteiramente casualizado com quatro tratamentos e 5 repetições. Após 45 dias, os silos foram abertos e procedeu-se à análise sensorial e retiradas de amostras para análise do nitrogênio amoniacal, pH, MS, PMS, PG, RMS e estabilidade aeróbia. A inclusão dos resíduos de fibra de curauá promoveu aumentos lineares de MS $(\mathrm{P}<0,05)$. Houve diferença significativa para as variáveis de PMS, PG, RMS, N-NH3/N-TOTAL. A inclusão do resíduo reduziu de forma linear as $\mathrm{PG}(\mathrm{P}<0,05)$, promoveu aumento no teor de N-NH3/NTOTAL $(\mathrm{P}<0,05)$ nos tratamentos com $0 ; 2,5$ e $5 \%$ de adição do resíduo de fibra de curauá e reduziu no tratamento com 7,5\%. Houve aumento nos valores de $\mathrm{pH}(\mathrm{P}<0,05)$. Com relação à temperatura $(\mathrm{P}<0,05)$, todas as silagens apresentaram valores de máximas entre $27,8^{\circ} \mathrm{C}$ e $28^{\circ} \mathrm{C}$. Apenas o tratamento com $2,5 \%$ de resíduo de curauá apresentou quebra de estabilidade. As silagens analisadas apresentaram pouca deterioração aeróbia. A inclusão do resíduo de fibra de curauá na silagem de capim-piatã contribuiu para o aumento da temperatura e do $\mathrm{pH}$ das silagens e as perdas de $\mathrm{N}-\mathrm{NH}_{3}$.

Palavras-chave: Alimentação animal; aditivos; ensilagem; resíduo agroindustrial;

\begin{abstract}
The work aimed to evaluate the fermentative characteristics, sensory analysis and aerobic stability of Piatã grass silages with the addition of curauá fiber residue. The experiment was carried out in the Laboratory of Bromatology of the Federal University of Oeste do Pará, the Piatã grass was ensiled at 43 days of regrowth, with inclusion of $0 ; 2.5 ; 5$ and $7.5 \%$ of curauá fiber residue. A completely randomized design with four treatments and 5 replications was used. After 45 days, the silos were opened and sensory analysis and samples were taken for analysis of ammonia nitrogen, $\mathrm{pH}, \mathrm{MS}, \mathrm{PMS}, \mathrm{PG}, \mathrm{RMS}$ and aerobic stability. The inclusion of curauá fiber residues promoted linear increases in $\mathrm{DM}(\mathrm{P}<0.05)$. There was a significant difference for the variables of PMS, PG, RMS, N-NH3/N-TOTAL. The inclusion of the residue linearly reduced the PG $(\mathrm{P}<0.05)$, promoted an increase in the content of N-NH3/N-TOTAL $(\mathrm{P}<0.05)$ in treatments with $0 ; 2.5$ and $5 \%$ addition of curauá fiber residue and reduced in the treatment with $7.5 \%$. There was an increase in $\mathrm{pH}$ values $(\mathrm{P}<0.05)$. Regarding temperature $(\mathrm{P}<0.05)$, all silages showed maximum values between $27.8^{\circ} \mathrm{C}$ and $28^{\circ} \mathrm{C}$. Only the treatment with $2.5 \%$ of curauá residue showed a break in stability. The analyzed silages showed little aerobic deterioration. The inclusion of curauá fiber residue in the Piatã grass silage contributed to the increase in temperature and $\mathrm{pH}$ of the silages and the loss of N-NH3.
\end{abstract}

Keywords: Animal feed; aditive; silage; agroindustrial waste; 


\section{INTRODUÇÃO}

A silagem, é definida como o produto de uma fermentação anaeróbica controlada de determinada forragem verde, armazenada em silos, com o propósito de preservar os nutrientes encontrados na forragem fresca, com o mínimo de perdas de matéria seca e energia (PEREIRA e SANTOS, 2006) e, apresenta-se como alternativa alimentar para melhorar a alimentação do rebanho, além de minimizar os efeitos da perda de peso e produção de leite durante os períodos de seca, pois a sazonalidade da produção forrageira é um dos maiores obstáculos à produção animal em pastagens na maior parte do Brasil, levando a períodos de aumento significativo na produção seguidos de escassez (FERNANDES et al., 2016; MODESTO et al., 2008). Portanto, gramíneas forrageiras como o capim-piatã, podem ser usadas como opção de diversificação de forragem, pois além da diversificação de pastejo, também pode ser utilizada para a produção de silagem (AZEVEDO, 2011).

A Brachiaria brizantha $\mathrm{cv}$. BRS Piatã se destaca por apresentar crescimento foliar elevado, grande disponibilidade de folha sob pastejo e bom valor nutricional (VALLE et al., 2010), além de apresentar boa adaptabilidade a solos moderadamente férteis e mal drenados, apresenta taxa de crescimento com níveis de saturação por bases entre 40 a 60\%, (EMBRAPA, 2007). A produtividade do capim-piatã varia de 8 a 12 t.MS/ha/ano, apresentando menor rendimento do que as outras variedades de B. brizantha, porém é mais tolerante à seca e também apresenta boa palatabilidade (RIBEIRO et al., 2016). Devido à sazonalidade de produção, as gramíneas tropicais não podem fornecer nutrientes suficientes para a produção máxima animal e, além das mudanças de temperatura e fotoperíodo, a estacionalidade das chuvas nas regiões tropicais não permite a produção uniforme de forragem durante o período de produção do ano (AZEVEDO, 2011).

As mudanças na composição da silagem são acompanhadas pelo aumento do $\mathrm{pH}$, temperatura e nitrogênio amoniacal, embora o nitrogênio amoniacal apresenta alterações inconsistentes devido às perdas variáveis por volatilização (McDONALD et al., 1991). Com isso, se faz necessário a utilização de aditivos como estratégia para obter silagens de alta qualidade, visando aumentar o valor nutricional, proporcionar a melhoria higiênica, limitar fermentações secundárias e trazer maior retorno econômico à produção animal (JOBIM et al., 2007). O uso de coprodutos agroindustriais pode ser uma opção 
para melhorar as propriedades químicas e fermentativas em silagens de capim, pois funcionam como fonte adicional de carboidratos para o processo fermentativo, além de elevar o valor nutritivo das silagens (POMPÉU et al., 2006).

O potencial de uso de resíduos de coprodutos da agricultura e sua utilização como aditivo na alimentação animal, possibilita a retirada de potenciais causadores de impacto ambiental e, de maneira conjunta, a possibilidade de obtenção de volumosos de melhor qualidade para a alimentação de ruminantes (BONFÁ et al., 2015). A fibra de curauá [Ananas comosus (L.) Merr. var. erectifolius (L. B. Smith), é uma espécie vegetal muito comum na Amazônia, pertencente à família Bromeliaceae, de porte herbáceo que apresenta duas variedades: a roxa e a branca (COPPENS e LEAL, 2003). As fibras de curauá, assim como as demais fibras lignocelulósicas, são constituídas de celulose, hemicelulose (ou polioses), lignina, pectina, cera e substâncias solúveis em água, sendo os três primeiros componentes majoritários e os responsáveis pelas propriedades físicas das fibras (GEORPOULOS et al., 2005; SPINACÉ et al., 2011).

Silva et al. (2014), relatam que da fibra do curauá sai uma mucilagem de alto valor proteico que pode ser oferecida aos animais. No entanto, a utilização de aditivo não dispensa a necessidade de cuidados normais da produção de silagem de boa qualidade, tais como, a idade de corte, compactação da forragem e fechamento dos silos (PACHECO et al., 2013). Objetivou-se avaliar as características fermentativas, análise sensorial e estabilidade aeróbia de silagens de capim-piatã aditivadas com diferentes níveis de resíduo de fibra de curauá.

\section{MATERIAL E MÉTODOS}

O capim-piatã foi plantado e colhido em uma área já implantada na Fazenda Experimental da UFOPA em Santarém-PA. O resíduo de fibra de curauá (Ananás erectifolius) foi coletado na comunidade de São Jorge na região do lago grande, Santarém-Pará. O experimento foi conduzido no Laboratório de Bromatologia da Universidade Federal do Oeste do Pará (UFOPA), unidade Tapajós, Santarém-PA. O delineamento experimental utilizado foi inteiramente casualizado, com quatro tratamentos e cinco repetições (T1: 0\%; T2: 2,5\%; T3: 5\% e T4: 7,5\% de adição de resíduo de fibra de curauá). As médias das variáveis de matéria seca, perdas de matéria seca, perdas por gases, recuperação de matéria seca, nitrogênio amoniacal e pH foram submetidas a análise de variância e regressão considerando $\mathrm{P}<0,05$. O software utilizado para resultar as análises foi SISVAR versão 5.6 (FERREIRA, 2011). 
O capim-piatã foi cortado manualmente aos 43 dias de rebrota e emurchecido ao sol por 1h para retirada de parte da umidade, após isso, o capim foi triturado com auxílio de uma picadeira estacionária em partículas de aproximadamente $2 \mathrm{~cm}$. O resíduo da fibra de curauá foi desidratado ao sol por 3 dias e picado em picadeira estacionária com tamanho médio de partículas de $2 \mathrm{~cm}$. A forrageira e os resíduos foram homogeneizados e compactados manualmente com soquetes de madeira em silos laboratoriais de PVC com $100 \mathrm{~mm}$ de diâmetro, $300 \mathrm{~mm}$ de comprimento de forma a atingirem uma densidade de $500 \mathrm{~kg} / \mathrm{m}^{3}$. Os silos foram fechados com tampas de PVC, providos de válvulas de Bunsen para escape dos gases oriundos de fermentação, lacrados com fita adesiva, pesados e armazenados. Aos 45 dias da ensilagem, os silos foram novamente pesados com propósito de avaliar as perdas por gases, perdas de matéria seca e recuperação de matéria seca. A avaliação sensorial das silagens ocorreu de acordo com metodologia descrita por Meyer et al. (1989), foram analisados os aspectos relacionados ao odor, coloração e manipulação (teor de Matéria Seca), para os quais as silagens receberam pontuações e, a partir da soma destas, as silagens foram classificadas com relação ao valor nutritivo e valor sanitário. Retirou-se amostras de 500g de silagem, colocadas em sacos de papéis e levados para a estufa de circulação forçada de ar a $55^{\circ} \mathrm{C}$ por $72 \mathrm{~h}$ para determinação dos teores de matéria pré-seca, por conseguinte, as amostras foram moídas em moinho do tipo Willey com peneira de malha de $1 \mathrm{~mm}$ de diâmetro e posteriormente determinados os valores de MS segundo a metodologia do AOAC (1990). Para determinação do nitrogênio amoniacal foram pesados $25 \mathrm{~g}$ de amostra das silagens com valores determinados conforme os critérios de Bolsen et al. (1992).

Para o ensaio de estabilidade aeróbia, foram feitas duas amostras compostas com 200g cada repetição (T1, T2, T3, T4) totalizando $1 \mathrm{~kg}$ de silagem por cada tratamento colocadas em baldes de polipropileno abertos, com capacidade de $8 \mathrm{~L}$, acondicionados em sala fechada com temperatura controlada $\left(27^{\circ} \mathrm{C}\right)$, as aferições de temperatura das silagens foram medidas duas vezes ao dia ( 8 e 18h) durante 7 dias com auxílio do termômetro digital inserido em profundidade de $10 \mathrm{~cm}$ da massa. Foram avaliados 14 tempos $(0,8,18,32,42,56,66,80,90,104,114,128,138,152$ horas após a abertura dos silos) e nos mesmos horários foram aferidos os valores de $\mathrm{pH}$ conforme os critérios descritos por Silva e Queiroz (2002). A determinação das perdas totais de Matéria Seca foi dada pela diferença entre o peso bruto de MS inicial e final dos silos, em relação à 
quantidade de forragem ensilada (MS). Foi descontado o peso do silo na silagem e na abertura, segundo equação proposta por Schmidt (2006).

As perdas por gases foram determinadas através da diferença de peso no dia do fechamento e abertura dos silos, em relação a quantidade de massa ensilada conforme equação descrita por Schmidt (2006).

A determinação de recuperação de Matéria Seca foi calculada de acordo com a equação descrita por Schmidt (2006).

\section{RESULTADOS E DISCUSSÃO}

Nas tabelas 01 e 02 estão descritas as avaliações sensoriais de capim-piatã com níveis de resíduo de fibra de curauá quanto aos aspectos nutritivos e sanitários, respectivamente. Com relação aos aspectos nutritivos, todas as silagens apresentaram resultados positivos variando de "Satisfatórias" a "Boa a muito boa", onde não revelaram alterações significativas nos parâmetros analisados, apresentando coloração tipicamente esverdeada, sem odor intenso de queimado e ao apertar com a mão não se notou um excesso de umidade o que sugere teores de MS adequados. Esses resultados podem estar relacionados com apropriado processo de ensilagem por meio da compactação, vedação e controle de densidade $\left(500 \mathrm{~kg} / \mathrm{m}^{3}\right)$.

Tabela 01: Avaliação sensorial das silagens de capim-piatã com inclusão de níveis de resíduo de fibra de Curauá quanto às características associadas ao valor nutritivo.

\begin{tabular}{cccc}
\hline $\begin{array}{l}\text { Níveis de inclusão } \\
\text { Parâmetro* }\end{array}$ & Pontuação & Classificação* & \\
\hline $0 \%$ & 19 & SATISFATÓRIA & 15 a 20 \\
$2,5 \%$ & 22 & BOA A MUITO BOA & 21 a 25 \\
$5 \%$ & 20,8 & SATISFATÓRIA & 15 a 20 \\
$7,5 \%$ & 22,2 & BOA A MUITO BOA & 21 a 25
\end{tabular}

*Conforme critérios estabelecidos por Meyer et al. (1989).

Com relação aos aspectos sanitários (Tabela 02), todas as silagens apresentaram resultados insatisfatórios, contendo em sua maioria odor de natureza alcoólica, presença de algumas leveduras e material levemente aquecido, o que sugere efeitos de fermentações secundárias. 
Tabela 02: Avaliação sensorial das silagens de capim-piatã com inclusão de níveis de resíduo de fibra de Curauá quanto às características associadas ao aspecto sanitário.
Níveis de inclusão
Pontuação
Classificação*
Parâmetro*

\begin{tabular}{cccc}
\hline $0 \%$ & $-12,8$ & INADEQUADA & $-11 \mathrm{a}-20$ \\
& & AVALIAR AS \\
$2,5 \%$ & POSSIBILIDADES DE & \\
& $-8,4$ & RISCO & $-6 \mathrm{a}-10$ \\
$5 \%$ & AVALIAR AS \\
$7,5 \%$ & $-10,8$ & POSSIBILIDADES DE & $-6 \mathrm{a}-10$ \\
& -14 & RISCO & $-11 \mathrm{a}-20$ \\
\hline
\end{tabular}

*Conforme critérios estabelecidos por Meyer et al. (1989).

As médias de matéria seca (MS), perdas de matéria seca (PMS), perdas por gases (PG), recuperação de matéria seca (RMS), nitrogênio amoniacal e pH na abertura do silo encontram-se na Tabela 03. Houve efeito significativo $(\mathrm{P}<0,05)$ entre os teores de MS das silagens com inclusão dos resíduos.

A adição do resíduo de fibra de curauá promoveu aumento linear na matéria seca de 2,19\% para cada unidade de resíduo adicionado à silagem. O aumento no teor de MS pode ser justificado pela incorporação do resíduo de fibra de curauá, que apresentou teor de MS de 18,70\% no momento da ensilagem. Apesar de todas as silagens apresentaram efetividade no aumento de MS, os resultados analisados (Tabela 03) mostram-se abaixo dos valores tidos como ideais por McDonald et al. (1991), onde consideram que para se obter uma silagem de boa qualidade os teores de matéria seca devem variar de 30 a 35\%, pois teores abaixo do preconizado promovem a proliferação de bactérias do gênero Clostridium, que são responsáveis por fermentação indesejáveis.

As silagens aditivadas com 7,5\% do resíduo apresentaram média de MS próximo ao teor mínimo considerado ideal. Esses resultados assemelham-se aos obtidos por Pereira et al. (1999), onde registraram aumentos lineares em relação aos teores de MS à medida em que se aumentou os níveis de polpa cítrica, no entanto, os teores de MS encontraram-se abaixo do recomendado. Monteiro et al. (2011) também observou teor de MS inferior ao considerado ideal de 28,26\% utilizando cana-de-açúcar como aditivo na silagem de capim-elefante. $O$ teor da matéria seca de uma silagem está totalmente relacionado com a proteólise na silagem, ou seja, quanto menor o conteúdo de MS no material ensilado maior será a degradação de proteínas (MUCK, 1990). 
Tabela 03 - Valores de matéria seca (MS), perdas de matéria seca (PMS), perdas por gases (PG), recuperação de matéria seca (RMS), nitrogênio amoniacal $\left(\mathrm{N}-\mathrm{NH}_{3}\right)$ e potencial hidrogeniônico $(\mathrm{pH})$ das silagens de capim-piatã aditivadas com níveis crescentes de resíduo de fibra de curauá.

\begin{tabular}{|c|c|c|c|c|c|c|c|c|}
\hline \multirow{3}{*}{ Variável } & \multicolumn{4}{|c|}{ Nível (\% da Matéria } & \multirow{3}{*}{ EPM } & \multirow{3}{*}{$\mathrm{P}$} & \multirow{3}{*}{ Equação de regressão } & \multirow{3}{*}{$\begin{array}{l}\mathrm{R}^{2} \\
(\%)\end{array}$} \\
\hline & & $\mathrm{Na}$ & ural) & & & & & \\
\hline & 0 & 2,5 & 5 & 7,5 & & & & \\
\hline $\mathrm{MS}(\% \mathrm{MN})$ & 20,06 & 21,88 & 23,31 & 26,87 & 0,43 & 0,05 & $Y=2,19 x+17,56$ & 95,73 \\
\hline PMS (\%) & 16,26 & 16,68 & 9,04 & 19,56 & 1,31 & 0,05 & $Y=2,52 x^{2}-12,4 x+27,4$ & 42,86 \\
\hline PG (\%) & 7,80 & 6,30 & 6,33 & 4,75 & 0,33 & 0,05 & $Y=-0,91 x+8,57$ & 89,41 \\
\hline $\operatorname{RMS}(\%)$ & 8,37 & 8,33 & 9,10 & 8,04 & 0,13 & 0,05 & $Y=-0,25 x^{2}+1,23 x+7,25$ & 42,69 \\
\hline $\begin{array}{l}\mathrm{N}-\mathrm{NH}_{3} \\
(\% \mathrm{NT})\end{array}$ & 2,51 & 3,77 & 5,57 & 4,35 & 0,34 & 0,05 & $Y=0,73 X+2,21$ & 55,40 \\
\hline $\mathrm{pH}$ & 4,72 & 4,79 & 4,93 & 5,11 & 0,05 & 0,05 & $Y=0,13 x+4,56$ & 96,05 \\
\hline TEMP $\left({ }^{\circ} \mathrm{C}\right)$ & 26,83 & 26,75 & 27,11 & 26,98 & 0,05 & 0,05 & $Y=0,13 x+85$ & 37,14 \\
\hline
\end{tabular}

*Significativo a 5\% de probabilidade. EPM- erro padrão da média.

Os valores das perdas de MS $(\mathrm{P}<0,05)$ das silagens variaram significativamente entre os níveis de resíduos adicionados (Tabela 03). A maior média observada foi de $19,56 \%$ para o tratamento com 7,5\% de resíduo adicionado à silagem e menor valor de 9,04\% na silagem aditivada com 5\% de resíduo. Estes resultados podem estar relacionados à uma possível presença de leveduras que segundo (WILKINSON e DAVIES, 2012) geram grandes perdas de matéria seca quando consomem os carboidratos residuais. Em relação as perdas por gases, verificou-se efeito significativo entre os tratamentos $(\mathrm{P}<0,05)$, com diminuição linear de 0,91 pontos percentuais para cada unidade de resíduo de fibra de curauá adicionado, apresentando perdas mínimas de 4,75\% no maior nível de inclusão $(7,5 \%)$ (Tabela 03).

Pacheco et al. (2014) relataram que as perdas por gases estão ligadas ao perfil fermentativo ocorrido na silagem, em que as menores perdas são causadas por bactérias homofermentativas, onde extinguindo as condições favoráveis para o desenvolvimento dos microrganismos produtores de gases, tais como as enterobactéria e bactérias clostrídicas, as perdas por gases tornam-se mínimas. As perdas por gases deste estudo foram maiores que a encontradas por Rezende et al. (2008) que ao analisarem diferentes aditivos em silagem de capim-elefante, observaram perdas por gases de $2,55 \%$ utilizando 
7\% de polpa cítrica. A adição do resíduo de fibra de curauá reduziu as perdas por gases, possivelmente devido à uma redução de microrganismos que produzem gases que se desenvolvem em silagens mal fermentadas (McDONALD, 1981).

Os índices de recuperação da MS apresentaram diferenças significativas entre os tratamentos $(\mathrm{P}<0,05)$. As silagens aditivadas com 5\% do resíduo apresentaram maior média de RMS de 9,10\% em relação aos demais tratamentos e menor média observada de 8,04 no tratamento com maior adição do resíduo de fibra de curauá $(7,5 \%)$, estes resultados podem ser explicados pelo aumento linear da MS devido o incremento do resíduo, resultando em possíveis diminuições de fermentações secundárias e consequentemente as perdas de matéria seca (Tabela 03).

Foram observados incrementos lineares significativos $(\mathrm{P}<0,05)$ nos teores de N$\mathrm{NH}_{3} / \mathrm{N}$-TOTAL (Tabela 03), com acréscimo de 0,73 pontos percentuais para cada $1 \%$ de inclusão de resíduo de fibra de curauá, os níveis 7,5 e 5\% de resíduo de fibra de curauá ofereceram maiores médias de concentrações de nitrogênio amoniacal de 4,35 e 5,57\%, respectivamente. $\mathrm{O}$ nitrogênio amoniacal, expresso como uma porcentagem do nitrogênio total, é uma propriedade importante na avaliação da silagem por indicar a quantidade de proteína que é degradada durante a etapa de fermentação ou potencial ocorrência de superaquecimento da massa no silo, ocasionando reações de "Maillard" (PIRES et al., 2013). Monteiro et al. (2011) encontrou valor médio de $\mathrm{N}-\mathrm{NH}_{3} / \mathrm{N}-\mathrm{TOTAL}$ de 3,67 utilizando cana-de-açúcar, valor inferior comparado as silagens aditivadas deste estudo. Já Bergamaschine et al. (2006) avaliando silagem de capim-marandu com adição de 10\% de polpa cítrica observaram teor de $\mathrm{N}^{-\mathrm{NH}_{3}}$ de 6,78 , constatando que a polpa cítrica reduziu a proteólise.

Segundo Van Soest (1994), o teor de N-amoniacal é um parâmetro indicativo da qualidade da silagem, considerada de alta qualidade quando apresenta teores abaixo de $10 \%$, com base neste parâmetro, os valores de nitrogênio amoniacal encontram-se dentro da faixa considerada desejável. Monteiro et al. (2011) ressaltam que quanto maior o teor de nitrogênio menor será a qualidade da silagem, devido a degradação de compostos proteicos até a formação de amônia, a qual é volatilizada durante a abertura do silo.

Verificaram-se valores de $\mathrm{pH}$ na pré-ensilagem entre 4,72 a 5,11, (Tabela 03). Os dados obtidos apresentaram diferença significativa nos níveis de $\mathrm{pH}(\mathrm{P}<0,05)$. A adição do resíduo não acelerou a queda do $\mathrm{pH}$ e sim promoveu aumentos lineares conforme os níveis de resíduo de fibra de curauá foram adicionados à silagem, com acréscimo de 
0,13\% a cada $1 \%$ de aumento do nível do resíduo. Os maiores valores de $\mathrm{pH}$ foram 4,93 e 5,11 nas silagens com níveis mais altos de inclusão do resíduo 5 e 7,5\%, respectivamente, com menor valor de $\mathrm{pH}$ foi de $4,72 \%$ na silagem exclusiva de capimpiatã. Os valores de $\mathrm{pH}$ das silagens analisadas ficaram acima dos parâmetros de 3,8 a 4,2, preconizados por McDonald et al. (1991) como indicativo de um processo fermentativo adequado. Amaral et al. (2008) apontam que o aumento do pH é resultado da degradação do ácido lático por microrganismos aeróbios para obtenção de energia, assim como a volatilização de outros ácidos orgânicos. No entanto, Neumann et al. (2009) destaca que as silagens que apresentam $\mathrm{pH}$ superior a 4,2, se levado em conta seu teor de matéria seca, podem ser classificadas como de boa qualidade. Com relação à temperatura $(\mathrm{P}<0,05)$, as médias foram maiores nas silagens com nível de inclusão de 5\% do resíduo de fibra de curauá $\left(27,11^{\circ} \mathrm{C}\right)$ e de menor valor nas silagens com $2,5 \%$ de inclusão do resíduo de fibra de curauá $\left(26,75^{\circ} \mathrm{C}\right)$, com acréscimo de $0,13 \%$ em cada unidade do resíduo adicionado a silagem (Tabela 03). O aumento inicial da temperatura é causado pela ação de leveduras e bactérias, mas após um período de tempo, outros microrganismos começam a causar deterioração do material (GIMENES et al., 2006; WOOLFORD, 1990).

A estabilidade aeróbia da silagem que de acordo com Kung Jr. et al. (2003) é um fator importante na qualidade da silagem, sendo definida como o tempo em que a silagem se eleva $2^{\circ} \mathrm{C}$ acima da temperatura ambiente após a abertura do silo. Houve diferenças significativas na estabilidade aeróbia entre os tratamentos $(\mathrm{P}<0,05)$. Todas as silagens apresentaram temperaturas máximas entre $27,8^{\circ} \mathrm{C}$ e $28^{\circ} \mathrm{C}$. O comportamento temporal das silagens está apresentado na Figura 01. As silagens ficaram expostas por 7 dias em aerobiose com temperatura controlada a $27^{\circ} \mathrm{C}$, as temperaturas do tratamento exclusivo de silagem de capim-piatã mantiveram-se abaixo da temperatura ambiente até às 32 horas.

Jobim et al. (2007) mencionam que a estabilidade da silagem após a exposição ao ar pode ser conservada ou afetada por múltiplos fatores tais como os biomecânicos, microbiológicos, físicos, aditivo utilizado e a vedação do silo, no entanto, se a silagem não se mantiver estável após a fermentação, a perda de estabilidade e produção de calor serão inevitáveis, provocando perdas maiores do que o esperado. Apenas o tratamento acrescido de $2,5 \%$ de resíduo de curauá apresentou quebra de estabilidade de $28^{\circ} \mathrm{C}$ a 152 horas de exposição aeróbia. O restante das silagens neste ensaio não atingiu elevação da 
temperatura de $2^{\circ} \mathrm{C}$ acima da temperatura ambiente para que ocorresse quebra de estabilidade dentro do período de tempo avaliado neste estudo (152 horas).

Figura 01 - Comportamento temporal das silagens aditivadas com níveis crescentes de resíduo de curauá durante o período de exposição aeróbia em relação à temperatura.

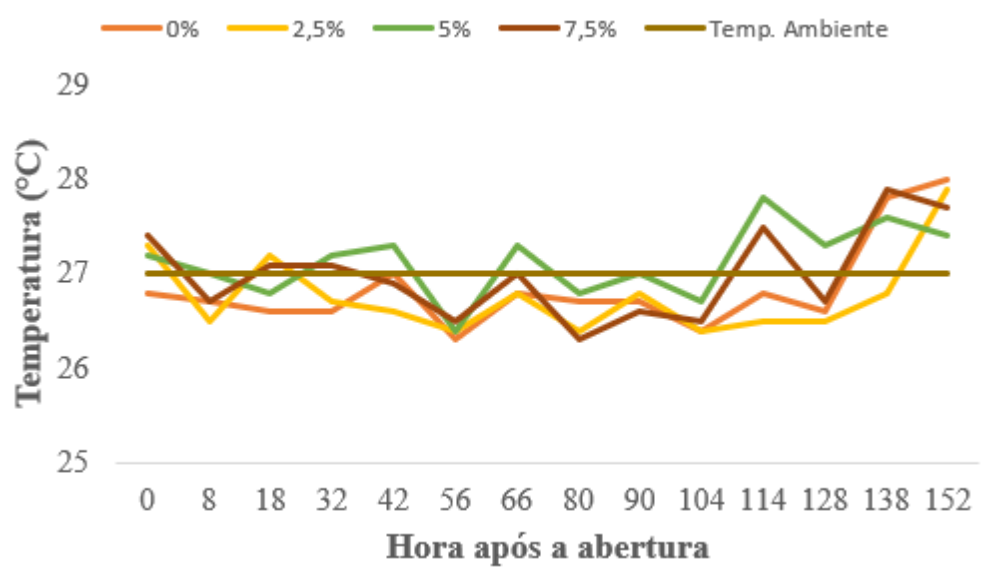

Os resultados deste estudo diferem dos resultados de Gomes (2012), que observou quebra de estabilidade aeróbia com 87 e 96 horas em silagens de capim-elefante com polpa cítrica e silagens de polpa cítrica, respectivamente. Os maiores níveis de resíduos adicionados ocasionaram elevação na temperatura média, esse aumento pode ser atribuído ao teor de MS proveniente do resíduo, favorecendo a fermentação da massa. Segundo Jobim et al. (2007), a avaliação de temperatura em um ambiente controlado pode não ser tão precisa para estimar a velocidade que ocorre a deterioração da silagem, pois não é a mesma que a situação de campo.

O processo de degradação aeróbia está diretamente relacionado ao aumento da temperatura e do $\mathrm{pH}$ provocado pelo metabolismo do açúcar e dos ácidos orgânicos causado por leveduras e bactérias, o que reduz a qualidade do material ensilado (SPOELSTRA et al., 1988). Desta forma, é possível afirmar que a silagem realizada neste experimento proporcionou pouca deterioração aeróbia. Os valores das médias de temperatura avaliados em todos os tratamentos encontram-se na faixa considerada ideal de 20 a $30^{\circ} \mathrm{C}$ para garantir estabilização e anaerobiose da massa ensilada, segundo preconizado por Betancourt et al. (2003).

Quanto ao $\mathrm{pH}$, ocorreu efeito significativo $(\mathrm{P}<0,05)$ com maiores médias de 5,25 e 5,48 observadas nos tratamentos com níveis mais altos de inclusão do resíduo 5 e 7,5\%, respectivamente, com acréscimo de $0,13 \%$ a cada $1 \%$ de resíduo adicionado, inferindo que maiores níveis de resíduo elevam os valores de $\mathrm{pH}$. Os níveis de $\mathrm{pH}$ neste experimento não corroboram com os teores observados por Gomes (2012), que avaliando 
a inclusão de polpa cítrica na silagem de capim-elefante observou diminuição do $\mathrm{pH}$ de 4,5 para 3,75. Enquanto Jayme (2008) obteve valor médio de $\mathrm{pH}$ de 3,80 em silagens de B. brizantha cv. Marandu aditivada com $30 \%$ de cana de açúcar. Segundo Kung Jr. et al. (2003) altos teores de $\mathrm{pH}$ podem ser um indicativo prático de que a silagem está sendo deteriorada devido à degradação dos ácidos orgânicos pelos efeitos indesejáveis de bactérias e fungos oportunistas os quais reduzem a qualidade da silagem quando exposta ao ar (KLEINSCHMIT et al., 2005). Porém, de acordo com Pacheco et al. (2014) o efeito inibitório sobre as bactérias depende da taxa de diminuição da concentração de íons e teor de umidade do meio, portanto o $\mathrm{pH}$ sozinho não é considerado um bom critério para avaliar a fermentação. As médias dos valores de pH podem ser avaliadas na Figura 02.

Figura 02 - Médias dos valores de $\mathrm{pH}$ das silagens de capim-piatã com diferentes níveis de resíduo de fibra de curauá. T1- 0\%, T2- 2,5\%, T3- 5\% e T4- 7,5\%.

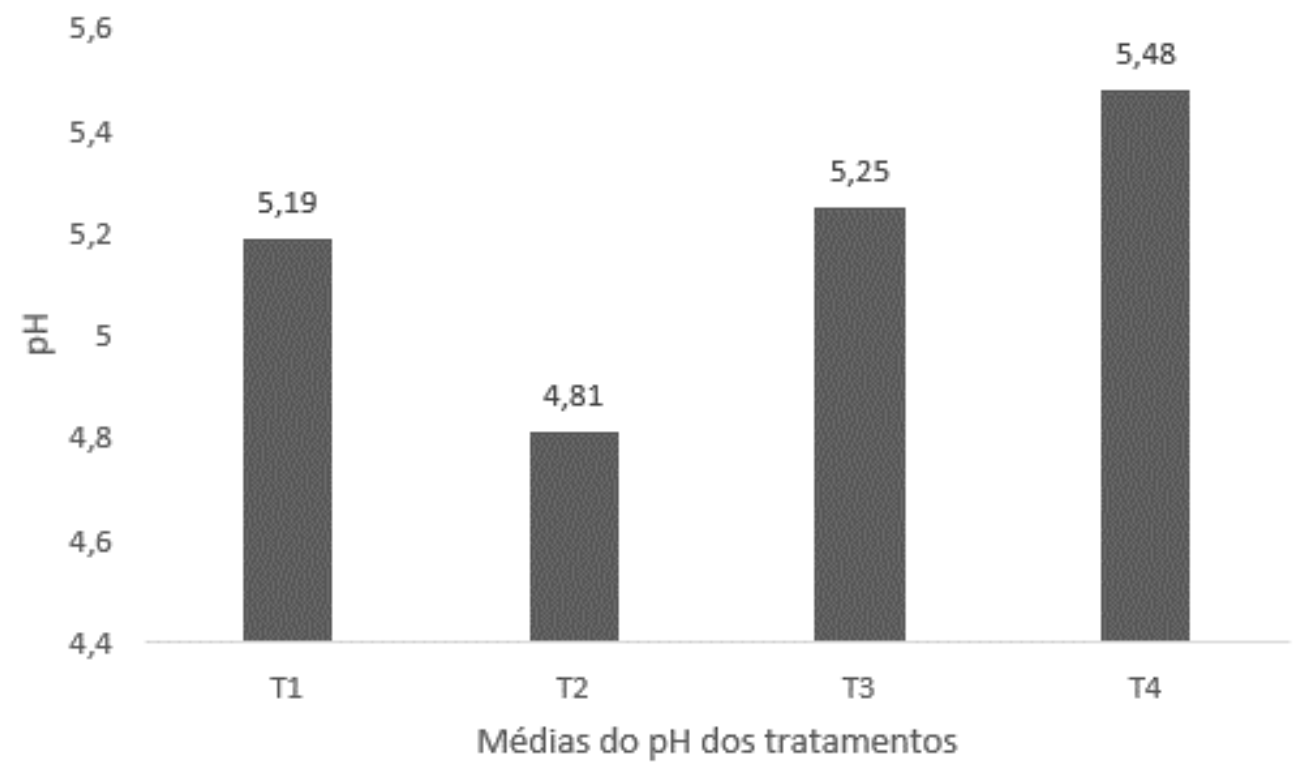

Os altos teores de $\mathrm{pH}$ obtidos neste estudo podem ser justificados pelos valores crescentes de matéria seca conforme o resíduo de fibra de curauá foi adicionado e possivelmente pela alta capacidade de tamponamento, definida por Jobim et al. (2007) como a capacidade de resistência da massa ao abaixamento do $\mathrm{pH}$, que indica que a presença de compostos nitrogenados leva ao aumento da capacidade tampão, portanto, quanto maior a capacidade tampão, maior a quantidade de ácido necessária para baixar o pH da silagem (PLAYNE e McDonald, 1966). Conforme Florentino et al. (2020), alto pH e longo período para que ocorra a queda, o meio tende a favorecer outros microrganismos indesejáveis, como as enterobactérias e clostridium, que competem com 
as bactérias ácido-láticas pelos carboidratos solúveis, aumentando as perdas de MS que podem gerar uma silagem de qualidade mais baixa.

No entanto, não só o valor final do pH é importante para a preservação da silagem, mas também a rápida acidificação do meio, responsável pela desnaturação das enzimas proteolíticas (WOOLFORD, 1984). De acordo com Evangelista et al. (2004), o teor de $\mathrm{N}-\mathrm{NH}_{3}$ e o valor de $\mathrm{pH}$ podem indicar a qualidade da fermentação. Apesar dos teores de $\mathrm{pH}$ terem ultrapassado a faixa recomendada, as silagens podem ser consideradas de boa qualidade devido ao baixo valor do nitrogênio amoniacal.

\section{CONCLUSÃO}

As silagens analisadas apresentaram características aceitáveis na análise sensorial, mas a adição do resíduo não promoveu resultados positivos em relação ao aspecto sanitário. A adição do resíduo à silagem, apesar de ter promovido aumentos nos teores de matéria seca, não foi suficiente para as silagens atingirem níveis de MS ideais. A inclusão do resíduo de fibra de curauá na silagem de capim-piatã contribuiu para o aumento da temperatura e do $\mathrm{pH}$ das silagens, reduziu as perdas por gases e de $\mathrm{N}-\mathrm{NH}_{3}$. Por fim, considerando os resultados positivos encontrados nesta pesquisa e a escassez de estudos aprofundados referente ao uso do resíduo de fibra de curauá utilizado na alimentação animal, ressalta-se a necessidade de realizar novas pesquisas com relação ao seu benefício para a nutrição animal.

\section{REFERÊNCIAS}

ASSOCIATION OF OFFICIAL ANALYTICAL CHEMISTS - AOAC. 1990. Official methods of analysis. 15.ed Arlington. v.1.1117p.

AZEVEDO, A.C.C.G. Composição bromatológica de silagens de capim xaraés e piatã emurchecidas e acrescidas de aditivos. 2011. Dissertação (Mestrado em AgronomiaProdução Vegetal) - Universidade Federal de Goiás, 2011.

BERGAMASCHINE, A.F.; PASSIPÉRI, M.; VERIANO FILHO, W.V.; ISEPON, O.J.; CORREA, L.A. Qualidade e valor nutritivo de silagens de capim-marandu (B. brizantha cv. Marandu) produzidas com aditivos ou forragem emurchecida. Revista brasileira de zootecnia, v. 35, p.1454-1462, 2006.

BETANCOURT, M.; MARTINEZ, M.; CLAVERO, T.; RAZZ, R.; PIETROSEMOLI, S.; FEBRES, O.A. Efecto de la melaza, ácido fórmico y tiempo de fermentación sobre el $\mathrm{pH}$ y temperatura en microsilos de Leucaena leucocephala. Revista Agronomia. 20(4), 493-501, 2003.

BOLSEN, K. K.; LIN, C.; BRENT, B. E.; FEYERHERM, A. M.; URBAN, J. E.; AIMUTIS, W. R. Effect of silage additives on the microbial succession and 
fermentation process of alfalfa and corn silages. Journal of Dairy Science, v.75, p.3066-3083, 1992.

BONFÁ, C. S.; CASTRO, G.H.F.; VILLELA, S.D.J.; SANTOS, R.A.; EVANGELISTA, A.R.; JAYME, C.G.; GONÇALVES, L.C.; PIRES, O.S.;

BARBOSA, J.A.S. Silagem de capim-elefante adicionada de casca de maracujá. Arq. Bras. Med. Vet. Zootec., v.67, n.3, p.801-808, 2015.

CLIMA-DATA. Clima: Santarém. Disponível em: https://pt.climate-data.org/americado-sul/brasil/para/santarem-4512/. Acesso em 17 junho de 2021.

COPPENS, G.; LEAL, F. Morphology, anatomy and taxonomy. In: BARTHOLOMEW, D. P.; PAULL, R.E.; ROHRBACH, K.G (Eds.). The pineapple: botany, production and uses. Wallingford: CABI, 2003.

EMBRAPA - Empresa Brasileira de Pesquisa Agropecuária. (2007). Brachiaria brizantha - BRS Piatã. Centro Nacional de Pesquisa de Gado de Corte, Campo Grande, Brasil.

EVANGELISTA, A.R.; ABREU, J.G.; AMARAL, P.N.C.; PEREIRA, R.C.; SALVADOR, F.M.; SANTANA, R.A.V. Produção de silagem de Capim-Marandu (Brachiaria brizantha stapf cv. Marandu) com e sem emurchecimento. Revista Ciência e Agrotecnologia, 2:446-452, (2004).

FERNANDES, G.F.; EVANGELISTA, A.F.; BORGES, L.S. Potencial de espécies forrageiras para produção de silagem: revisão de literatura. Nutritime Revista Eletrônica, v.13, n.3, p.4652-4656, 2016.

FERREIRA, D.F. Sisvar: A computer statistical analysis system. Ciência e Agrotecnologia, Lavra, MG, v.35, n.6, p.1039-1042, nov/. dez. 2011.

FLORENTINO, L.; NASCIMENTO, I.; SANTOS, R.; BORCHAT, K.; OLIVEIRA, A.; SILVA, M. Análise das perdas em silagem de cana-de-açúcar submetida a diferentes tipos de aditivos químicos. Enciclopédia Biosfera, v. 17, n.34, p. 22, 2020.

GEORPOULOS, S.T.; TARANTILI, P.A.; AVGERINOS, E.; ANDREPOULOS, A.G. \& KOUKIOS, E.G- POLYM. Degrad. Stabil., 90, p.303, 2005.

GIMENES, A.L.G.; MIZUBUTI, I.Y.; MOREIRA, F.B.; PEREIRA, E.S.; RIBEIRO, E.L.A.; MORI, R.M. Composição química e estabilidade aeróbia em silagens de milho preparadas com inoculantes bacteriano e/ou enzimático. Acta Scientiarum. Animal Sciences, v. 28, n. 2, p. 153-158, 2006.

GOMES, R.S. Uso de polpa cítrica e emurchecimento na ensilagem de capim-elefante. 2012. Dissertação (Programa de Pós-Graduação em Zootecnia) - Universidade Federal Rural do Rio de Janeiro, 2012.

JAYME, C.G. Silagens de Brachiaria brizantha sem aditivo, adicionada de cana-deaçúcar e aditivos bacterianos. 2008. Tese (Doutorado em Zootecnia) - Escola de Veterinária da Universidade Federal de Minas Gerais - UFMG, 2008. 
JOBIM, C.; NUSSIO, L.; REIS R.; SCHMIDT, P. Avanços metodológicos na avaliação da qualidade da forragem conservada. Revista Brasileira de Zootecnia, v.36, p.101119, 2007.

KLEINSCHMIT, D. H.; SCHMIDT, R. J.; KUNG JR., L. The Effects of Various Antifungal Additives on the Fermentation and Aerobic Stability of Corn Silage.

Journal of Dairy Science, v. 88, p. 2130-2139, 2005.

KUNG JR., L.; STOKES, M. R.; LIN, C. J. Silage additives. In: BUXTON, D. R.; MUCK, R. E.; HARRISON, J.H. (Eds.). Silage science and technology. Wisconsin: ASA; CSSA; SSSA, 2003. p. 305-360.

McDONALD, P. The biochemistry of silage. New York: John Wiley \& Sons, 1981. 207p.

McDONALD, P.; HENDERSON, A.R.; HERON, S. J. E. Biochemistry of silage. 2. ed. Marlow: Chalcombe, 1991. 340 p.

MEYER, H.; BRONSCH, K.; LIEBETSEDER, J. Supplemente zu Vorlesungen und bungen inder Tierernhrung. Verlag M. e H. Schaper, Hannover, 1989.

MODESTO, E.C.; SANTOS, G.T.; ZAMBOM, M.A.; DAMASCENO, J.C.; BRANCO, A.F.; VILELA, D. Consumo, digestibilidade e parâmetros ruminais em vacas gestantes alimentadas com silagem de rama de mandioca. Revista Brasileira de Zootecnia, v.37, n.5, p.944-950, 2008.

MONTEIRO, I.J.G.; ABREU, J.G.; CABRAL, L.S.; RIBEIRO, M.D.; REIS, R.H.P. Silagem de capim-elefante aditivada com produtos alternativos. Acta Scientiarum.

Animal Sciences, v. 33, n.4, p.347-352, 2011.

MUCK, R.E. Dry matter level on alfafa silage quality. II. Fermentation products and starch hydrolysis. Transaction of ASAE, v.33, n.2, p.373-381, 1990.

NEUMANN, M.; OLIBONI, R.; OLIVEIRA, M.R.; GÓRSKI, S.C.; FARIA, M.V.; UENO, R.K.; MARAFON, F. Girassol (Helianthus annuus L.) para produção de silagem de planta inteira. Pesquisa Aplicada \& Agrotecnologia, v. 2, n. 3, 2009.

PACHECO, W. F.; CARNEIRO, M. S. S.; PINTO, A. P.; EDVAN, R.L.; ARRUDA, P.C.L.; CARMO, A.B.R. Perdas fermentativas de silagens de capim-elefante com níveis crescentes de feno de Gliricídia. Acta Veterinária Brasílica, v.8, n.3, p. 155-162, 2014.

PACHECO, W.F.; CARNEIRO, M.S.S.; EDVAN, R.L.; ARRUDA, P.C.L.; CARMO, A.B.R. Valor nutritivo de silagens de capim elefante (Pennisetum purpureum, Schum) com feno de gliricídia (Gliricidia sepium (Jacq.) Walp). Revista Verde de Agroecologia e Desenvolvimento Sustentável, v.8, n.2, p.240-246, 2013.

PEREIRA, O.G.; SANTOS, E.M. Microbiologia e o Processo de Fermentação em Silagens. In: SIMPÓSIO SOBRE MANEJO ESTRATÉGICO DA PASTAGEM, Anais... Viçosa, MG: UFV, 2006. p.393-430. 
PEREIRA, R.C.; BANYS, V.L.; SILVA, A.C.; PEREIRA, R.G.A. Adição de polpa cítrica peletizada na ensilagem de capim-elefante (Pennisetum purpureum Schum) cv. Cameroon. Ver. Univ. Alfenas, 5: 147-152, 1999.

PIRES, D. A. de A.; ROCHA JÚNIOR, V.R.; SALES, E.C.J.; REIS, S.T.; JAYME, D.G.; CRUZ, S.S.; LIMA, L.O.B.; TOLENTINO, D.C.; ESTEVES, B.L.C.

Características das silagens de cinco genótipos de sorgo cultivados no inverno. Revista Brasileira de Milho e Sorgo, Sete Lagoas, v. 12, n. 1, p. 68-77, 2013.

PLAYNE, M.J.; MCDONALD, P.T. The buffering constituents of herbage and of silage. Journal of the Science of Food and Agriculture, v. 17, p. 264-268, 1966.

POMPÉU, R.C.F.F.; NEIVA, J.N.M.; CÂNDIDO, M.J.D.; FILHO, G.S.O.; AQUINO, D.C.; LOBO, R.N.B. Valor nutritivo de silagens de capim-elefante (Pennisetum purpureum Schum.) com adição de subprodutos do processamento de frutas tropicais. Revista Ciência Agronômica, v.37, n.1, p.77-83, 2006.

REZENDE, A.V.; GASTALDELLO JUNIOR, A.L.; VALERIANO, A.R.; CASALI, A.O.; MEDEIROS, L.T.; RODRIGUES, R. Uso de diferentes aditivos em silagem de capim-elefante. Ciência e Agrotecnologia, v.32, n.1, p.281-287, 2008.

RIBEIRO, T.B.; LIMA, W.M.; RIBEIRO, F.M.; BUSO, W.H.D. Características de algumas gramíneas do gênero Brachiaria. Revista Eletrônica Nutritime, v. 13, n. 4, p. 4773-4780, 2016.

SCHMIDT, P. Perdas fermentativas na ensilagem, parâmetros digestivos e desempenho de bovinos de corte alimentados com rações contendo silagens de cana-de-açúcar. Tese de doutorado. 2006. 228p. Universidade de São Paulo, Escola Superior de Agricultura Luiz de Queiroz.

SILVA, D.J.; QUEIROZ, A.C. Análise de Alimentos (Métodos Químicos e Biológicos). UFV, Imprensa Universitária, 2002. 235p, 2002.

SILVA, T.A.L.; BRESOLIN, I.R.A.P.; TAKAKI, G.M.C.; AOYAMA, H.; TAMBOURGI, E.B. Extraction and Preliminary Characterization of Bromelain from Curaua (Ananas erectifolius L.B. SMITH) Purple and White. Cheemical Engineering Transactions, v. 37, 2014.

SPINACÉ, M.A.S.; JANEIRO, L.G.; BERNARDINO, F.C.; GROSSI, T.A. \& De Paoli, M.a. Polimeros, 21, p.168 (2011). http://dx.doi.org/10.1590/S010414282011005000036 .

SPOELSTRA, S.F.; COURTIN, M.G.; VAN BEERS, J.A.C. Acetic acid bacteria can initiate aerobic deterioration of whole crop maize silage. J. Agric. Sci., Cambridge, v. 111, p. 127-132, 1988.

VALLE, C.B.DO.; MACEDO, M.; EUCLIDES, V.P.B.; JANK, L.; RESENDE, R.M.S. Genero Brachiaria. In: FONSECA, D.M; MATUSCELLO, J.A. (Ed.). Plantas

Forrageiras. Viçosa, MG: Ed. UFV, 2010, p. 30-77. 
VAN SOEST, P.J. Nutritional ecology of the ruminant. Ithaca: Cornell University, 1994. 476p.

WILKINSON, J. M.; DAVIES, D. R. The Aerobic Stability Of Silage: Key Findings And Recent Developments. Grass And Forage Science, v.68, p.1-19, 2012.

WOOLFORD, M.K. The detrimental effects of air on silage. Journal of Applied Bacteriology, v.68, p.101-116, 1990.

WOOLFORD, M.K. The silage fermentation. New York: Marcel Dekker, 1984. 350 p.

Recebido em: 15/09/2021

Aprovado em: 03/10/2021

Publicado em: 05/10/2021 